\title{
Flourshing Pada Womenpreneur di Daerah Istimewa Yogyakarta
}

\author{
Rusyda Nurul Fajri Daulay, Purwadi, Nina Zulida Situmorang \\ Fakultas Psikologi Universitas Ahmad Dahlan \\ Email: rusydadaulay22@gmail.com purwadipsik0@ gmail.com nzsitumorang@ gmail.com
}

\begin{abstract}
Every individual has the potential to achieve flourish, including mompreneurs in order to achieve a good life by optimizing their drastic potential. Based on this, it aims to determine the flourshing women preneuer and the aspects forming the flourishing women preneuer in the Special Region of Yogyakarta.Qualitative method with a phenomenological approach, interview data collection techniques were carried out on 6 womenpreneuer subjects. Triangulation was carried out by interviewing the subject's closest person. The sampling technique used purposive sampling. The results show that the six subjects have flourished by showing the five aspects of PERMA, namely positive emotion, engagement, positive relationship, meaning of life, accomplishment in their life.
\end{abstract}

Keywords: flourishing, PERMA, women preneur

\begin{abstract}
Abstrak
Setiap individu berpotensi untuk mencapai flourish, termasuk mompreneur agar mencapai kehidupan yang baik dengan mengoptimalkan potensi drinya. Berdasarkan hal tersebut bertujuan untuk mengetahui flourshing women preneuer dan aspek-aspek pembentuk flourishing women preneuer di Daerah Istimewa Yogyakarta. Metode kualitatif dengan pendekatan fenomenologi, teknik pengambilan data wawancara dilakukan pada 6 subjek womenpreneuer. Triangulasi dilakukan dengan wawancara orang terdekat subjek. Teknik pengambilan sampel menggunakan sampel purposive. Hasil menunjukkan bahwa ke enam subjek telah flourish dengan menunjukkan kelima aspek PERMA yaitu positive emotion, enggagment, positive relationship, meaning of life, accomplishment dalam kehidupan mereka.
\end{abstract}

Kata kunci: flourishing, PERMA, women preneur

\section{Pendahuluan}

Women preneur mampu flourish dalam aktivitasnya sebagai ibu rumah tangga dan entrepreneur, berarti telah mencapai tingkat kesejahteraan yang tinggi. Seseorang yang mencapai flourishing, yaitu terpenuhi aspek emosi positif serta mampu berfungsi secara psikologis maupun sosial dengan baik. Sebaliknya, women preneur yang tidak mampu flourish atau disebut juga dengan languish cenderung memiliki tingkat kesejahteraan yang rendah. Languishing dapat dianggap sebagai kehidupan yang hampa dan stagnan, tidak terlibat penuh serta memunculkan respon yang maladaptif [1]. Tidak semua wanita berkeluarga entrepreneur siap dengan segala konsekuensi yang akan dihadapinya. Seringkali wanita yang sudah berkeluarga merasa kewalahan dan berujung pada stress ketika menjalankan perannya dirumah tangga serta perannya sebagai wanita entrepreneur. Hal tersebut diungkap juga oleh Apreviadizy dan Puspitacandri [2], dari hasil penelitiannya diperoleh hasil bahwa ada perbedaan stres antara ibu yang bekerja dan ibu yang tidak bekerja, ibu yang bekerja lebih banyak mengalami stress dari pada ibu yang tidak bekerja. Setiap individu berpotensi untuk mencapai flourish, yang dapat diwujudkan dengan mengoptimalkan kemampuannya sesuai dengan virtue dan strengths masingmasing individu. Oleh karena itu setiap individu memiliki strategi berbeda dalam menjalani kehidupan yang baik, misalnya jika dilihat berdasarkan gender dan pekerjaannya. Seperti fenomena yang terjadi belakangan ini dimana berkembangnya minat wanita untuk bekerja sebagai entrepreneur. woman preneur bisa melalui berbagai hal untuk mencapai flourish, baik dari internal dirinya maupun eksternal.

Diterima Redaksi : 06-11-2020 | Selesai Revisi : 27-04-2021 | Diterbitkan Online : 28-04-2021 
Melihat fenomena womenpreneur yang diuraikan sebelumnya,penulis tertarik untuk meneliti bagaimana flourishing pada woman preneur dan aspek-aspek yang membentuk flourishing woman preneur di Yogyakarta.

\section{Metode Penelitian}

Penelitian ini menggunakan metode kualitatif, dengan pendekatan fenomenologi. Penelitian kualitatif digunakan untuk mengetahui fenomena apa yang dialami oleh subjek penelitian, seperti perilaku, tindakan dan lainnya secara holistik, dan dengan cara deskripsi dalam kata-kata dan bahasa[3]. Pengambilan data dilakukan dengan metode wawancara semi terstruktur. Wawancara semi terstruktur dilakukan agar pertanyaan yang diajukan tidak terlalu kaku. Penelitian ini menggunakan analisis isi karena peneliti ingin melihat secara mendalam dan menginterpretasi makna dibalik ucapan responden tentang bagaimana flourishing wanita entrepreneur yang sudah berkeluarga. Menurut Holsti [3] analisis isi adalah teknik apa pun yang digunakan untuk menarik kesimpulan melalui usaha menemukan karakteristik pesan, dan dilakukan secara objektif dan sistematis. Validitas dalam penelitian ada dua yaitu validitas internal dan validitas eksternal. Validitas eksternal berkaitan dengan keakurasian hasil penelitian yang dapat digeneralisasikan dan diterapkan pada populasi tempat sampel tersebut diambil. Sedangkan validitas internal berkaitan dengan keakurasian desain penelitian dengan hasil yang dicapai [4].

Untuk keterpercayaan peneltian, peneliti menggunakan triangulasi dengan mewawancarai orang terdekat subjek. Triangulasi dalam pengujian ini diartikan sebagai pengecekan data dari berbagai sumber dengan berbagai cara, dan berbagai waktu [5]. Data akan lebih diyakini kebenarannya jika dua sumber atau lebih menyatakan yang sama Sampel yang digunakan yaitu sampel purposive, sampel purposive adalah teknik pengambilan sampel sumber data dengan pertimbangan tertentu [5]. Purposive sample digunakan agar data yang dihasilkan dapat memenuhi tujuan dari penelitan ini, yakni untuk memperoleh bagamana flourishing wanita enterpreneur yang sudah berkeluarga, serta dapat menemukan hal-hal baru yang bisa diperoleh di lapangan berkaitan dengan flourishing.

Subyek penelitian dalam hal ini wanita entrepreneur yaitu wanita entrepreneur yang sudah berumah tangga berusia 30 tahun ke atas, menjalankan usaha minimal 3 tahun. Subjek pada penelitian ini adalah entrepreneur yang jenis usahanya tergolong pada usaha mikro. Kriteria usaha mikro yang dimaksud sesuai dengan isi Undang-Undang 20/2008 tentang UMKM pada BAB IV pasal 6, yang menenukan jenis UMKM berdasarkan hasil penjualan pertahun, suatu usaha dikatakan usaha mikro jika memiliki hasil penjualan tahunan paling banyak Rp. 300.000.000,00 (tiga ratus juta rupiah). Berikut karakteristik subjek pada penelitian ini:

Tabel 1. Karakteristik subjek penelitian

\begin{tabular}{|c|c|c|c|c|c|}
\hline No & $\begin{array}{l}\text { Nama/ } \\
\text { inisial }\end{array}$ & Usia & Jenis usaha & Hasil penjualan pertahun & Lama usaha \\
\hline 1. & TY & 35 th & Hijab fashion & \pm Rp. 200.000 .000 & 4 tahun \\
\hline 2. & UM & 32 th & Fashion batik & \pm Rp. 150.000 .000 & 6 tahun \\
\hline 3. & LI & 39 th & Produsen tas kulit & \pm Rp. 200.000 .000 & 5 tahun \\
\hline 4. & PG & 37 th & Fashion muslim bridal & \pm Rp. 100.000 .000 & 6 tahun \\
\hline 5. & ID & 35 th & $\begin{array}{l}\text { Produk } \\
\text { kecantikan/skincare }\end{array}$ & \pm Rp. 175.000 .000 & 3 tahun \\
\hline 6. & AN & 35 th & Produksi bantal & \pm Rp. 50.000 .000 & 4 tahun \\
\hline
\end{tabular}

\section{Hasil dan Pembahasan}

Flourishing pada Psikologi Positif dikembangkan oleh Martin Seligman dikenal dengan PERMA, yaitu positive emotion, engagement, relationship, meaningfullness dan accomplishment [6]. Flourishing pada pendekatan Psikologi positif meliputi pendekatan hedonic dan eudae monic sebagai pendekatan kesejahteraan dan juga terkait secara tidak langsung dengan kesejahteraan objektif. Kemudian dijelaskan juga bahwa flourishing ialah berkembangnya seseorang secara penuh dimana virtue dan strength diwujudkan secara penuh. Hal tersebut terjadi, hanya jika sesorang telah menjalani hidup dengan baik [7]. 
Individu yang mengalami flourishing memiliki sikap positif terhadap diri sendiri, merasa optimis akan kehidupan dan masa depan, memiliki kemampuan untuk mengatasi dan beradaptasi terhadap masalah yang terjadi dalam kehidupan. Individu yang flourish akan memiliki kesadaran akan kemampuan dan semangat untuk mengembangkan potensinya, terbuka pada pengalamaan baru serta memiliki kemampuan untuk mengendalikan emosi-emosi yang muncul agar tetap stabil, dan lebih merasakan emosi-emosi positif walaupun dirinya dalam keadaan yang tidak menyenangkan. Individu yang mengalami flourishing akan menganggap setiap pengalaman hidupnya bernilai serta mengarahkan setiap pengalaman tersebut pada pencapaian tujuan hidup, memiliki hubungan yang postif dengan orang lain dan sebagai anggota masyarakat turut berkontribusi dalam kegiatan masyarakat. Hal tersebut menunjukkan bahwa florishing adalah tingkat tertinggi dari well-being.[8] [9]

Profil dari individu yang flourish yaitu memiliki kemampuan beradaptasidan dan menerima kondisi lingkungan sosial yang tinggi, memiliki tingkat deoresi dan kecemasan yang rendah [1]. Begitu juga dengan pendapat Keyes yang menelliti flourishing sebagai lambang dari kesehatan mental yang baik [10]. Flourishing yang dialami setiap individu memiliki kaitan erat dengan istilah Complete Mental Health (CMH: kesehatan mental yang penuh/lengkap). CMH terdiri dari tiga elemn utama, yang pertama tidak adanya sakit mental, keduanya adanya kebahagiaan dan kepuasan dalam kehidupan secara konsisten. Ketiga kesejahteraan sosial seperti relasi yang akrab dan mendukung [11].

Wawancara pada 6 subjek utama penelitian dan didukung oleh 6 subjek pelengkap yang merupakan orang terdekat dari setiap subjek diperoleh beberapa tema atau aspek-aspek yang menunjukkan kondisi flourishing subjek. Aspek pertama berkaitan dengan emosi positif (positive emotion), Berdasarkan hasil penelitian keenam subjek merasakan emosi positif dalam setiap aktivitasnya, baik itu aktivitas di rumah maupun lingkungan pekerjaannya. Jika individu mengharapkan flourishing maka ia harus lebih banyak mengembangkan emosi positif, karena individu tersebut akan lebih sering melakukan upaya building yang akan senantiasa mengubah dirinya menjadi lebih baik dari waktu kewaktu [12]. Emosi positif yang dirasakan keenam subjek seperti senang, nyaman dan bahagia ketika melakukan pekerjaan yang disukai subjek sebagai entrepreneur. Emosi positif berupa perasaan optimis ketika subjek menerima komplain dari konsumen, subjek menjadikannya sebagai pelajaran untuk agar lebih baik kedepannya. Subjek juga merasa bersyukur dengan kehidupan yang kini ia jalani, subjek merasa puas dan bersyukur ketika konsumen memberikan review positif, subjek bersyukur memiliki keluarga yang mendukung pekerjaan subjek. Rasa syukur terhadap segala sesuatu dalam hidupnya berpengaruh pada kebahagiaan yang kemudian memunculkan emosi positif yang dapat membantu individu menghadapai berbagai kondisi dalam hidupnya.

Aspek kedua yaitu keterlibatan (engagement), engagement ialah sebuah jalan hidup dimana individu tidak hidup bagi diri sendiri, melainkan mengikat dengan seseorang, kelompok dan visi atau tujuan [7]. Pekerjaan sebagai entrepreneur dilakukan keenam subjek dengan berusaha meningkatkan kulitas usaha yang mereka miliki, baik dari segi kulitas produk, pelayanan maupun dari diri subjek sendiri. Keenam subjek melakukan hal tersebut karena subjek menikmati dan menyukai pekerjannya. Selain aktivitasnya di lingkungan pekerjaan, subjek juga memiliki kewajiban sebagi ibu rumah tangga, subjek mampu mengatur waktu antara pekerjaan dengan kewajibannya sebagai istri dan ibu. Hal tersebut menunjukkan keterlibatan subjek dalam menjalankan kehidupannya, keterlibatan adalah aktivitas yang ditunjukkan dari tingginya ketertarikan, dan menikmati setiap hal yang dilakukan dalam hidupnya.

Pada PERMA sebagai pembentuk flourishing secara tidak langsung juga mempengaruhi kesehatan dan finansial. Achievement/acomplisment dan engagement akan membuat seseorang mengembangkan diri dan melakukan pekerjaan yang terlibat penuh dengan emosi, sehingga akan memiliki kontribusi dan pengembangan diri yang baik. Hal ini akan berdampak positif pada karirnya. Pada dimensi engagement akan terkait dengan proses yang menyenangkan dan menghasilkan kontribusi yang optimal dalam bekerja, sehingga akan berdampak pada karir seseorang. Ketika seorang entrepreneur engaged, ia akan merasakan dorongan untuk berusaha untuk mencapai tujuan yang menantang dan ingin meraih kesuksesan. Individu yang engaged terhadap pekerjaannya bukan saja memiliki kapasitas energi untuk menjadi energik namun juga secara antusias memberikan kapasitas energi yang dimiliki untuk pekerjaannya [13].

Subjek melakukan pekerjaannya dengan langsung terlibat dalam setiap aktivitas pada pekerjaan itu, seperti mempercepat proses pengerjaan produk pesanan konsumen, melakukan promosi dan tetap mengikuti tren pasar. Subjek juga Bergabung dengan komunitas entrepreneur agar lebih banyak berkomunikasi dengan orang lain, untuk mengetahui info tentang tempat penjualan yang baik dan bisa 
berbagi ilmu atau pengalaman tentang dunia wirausaha. Aktivitas-aktivitas yang dilakukan subjek pada pekerjaannya tidak membuat subjek melalaikan tugasnya dikeluarga, keenam subjek tetap memprioritaskan keluarga dari pada pekerjaannya, seperti tetap mengurus keperluan anak, menyelesaikan pekerjaan rumah terlebih dahulu sebelum menjalankan aktivitas dipekerjaan subjek.

Aspek ketiga adalah hubungan yang positif (positive relationship), keenam subjek memiliki positive emotion baik dengan keluarga maupun dengan kryawan di lingkungan kerja. Suami-suami keenam subjek sangat memberi dukungan kepada subjek, seperti membantu pekerjaan subjek, memberikan beberapa solusi ketika subjek memiliki masalah pada pekerjaannya. Anak-anak subjek yang mengerti dengan pekerjaan ibunya, yang tentu sebelumnya diberi penjelasan oleh subjek agar anak-anak memahami bagaimana pekerjaan ibunya. Positive relationship itupun terjalin di lingkungan kerja subjek, karyawan yang sudah lama saling mengenal dengan subjek hingga menganggap karyawannya seperti keluarga sendiri. Selain itu subjek juga melibatkan karyawannya untuk memberikan ide-ide terkait produk, pemasaran dan juga pelayanan pada konsumen. Subjek dengan karyawannya bukan hanya mengkomunikasikan yang berhubungan pekerjaan saja bahkan persoalan pribadipun karyawan subjek menceritakannya, karena hubungan yang terjalin sudah dekat membuat karyawan percaya pada subjek. Hubungan yang dibangun secara positif akan berimplikasi pada flourishing [14]. Individu yang flourish ditunjukkan antara lain dengan kebaikan-kebaikan eksternal, seperti keluarga yang baik, teman-teman yang baik, keturunan yang baik serta senang dalam melakukan aktifitas-aktifitas yang baik [15].

Aspek keempat yaitu makna hidup (meaning of life), kehidupan yang sehat ialah kehidupan yang penuh makna [16]. Makna hidup dapat diwujudkan dengan sebuah keinginan untuk menjadi individu yang berguna bagi orang lain baik anak, istri/suami, keluarga dekat, negara bahkan umat manusia. Mengacu pada pendapat dari Frankl, subjek memiliki makna hidup dengan mewujudkan keinginannya yaitu mampu menyeimbangkan antara keluarga dan pekerjaan. Hal tersebut menjadi suatu keinginan subjek karena bagi keenam subjek keluarga tetap menjadi prioritas utamanya. Keluarga adalah alasan utama keenam subjek memilih bekerja sebagai enterpreneur. Karena dengan memiliki usaha sendiri keenam sujek bisa mengatur jadwal pekerjaan sendiri. Peran subjek sebagai istri dan ibu tetap bisa dijalankan dengan semaksimal mungkin walaupun keenam subjek memiliki pekerjaan. Flourishing berhubungan dengan kebahagiaan berdasarkan pencapaian hidup yang bermakna dan juga tentang kebajikan hidup, tercapainya tujuan perkembangan, yaitu "melakukan apa yang seharusnya dilakukan" [17]. Subjek merasakan kehidupannya bermakna karena adanya nilai-nilai yang penting bagi dirinya yaitu menganggap semua aktivitas dalam hidupnya adalah suatu ibadah kepada Allah. Sehingga membuat subjek menjalani kehidupannya dengan selalu bersabar bersyukur dan menikmati hidup dalam segala situasi. Makna hidup merupakan sebuah keyakinan dan cita-cita yang paling mulia yang dimiliki inidividu. Setiap ndividu menginginkan suatu makna hidup yang akan mewarnai perilaku dan batinnya, yang akan dijadikan arahan untuk segala kegiatan dan keberadaannya di dunia [18].

Aspek yang kelima adalah pencapaian (accomplisment), Keenam subjek mampu mencapai keadaan hidup yang diinginkannya. Seperti kemampuan yang kini dimiliki subjek sebagai entrepreneur. Seperti mampu memproduksi barang sendiri, bisa mempromosikan usaha sendiri dan bisa memperkerjakan orang lain. Kemampuan-kemampuan itu yang kemudian menjadikan usaha yang dimiliki subjek berkembang dengan baik. Flourishing berhubungan dengan pengalaman perjalanan kehidupan yang dijalani dengan baik. Merupakan gabungan antara perasaan yang baik dan berfungsi dengan efektif pula [19]. Subjek juga kini memiliki ekonomi yang lebih baik dari sebelumnya, subjek mampu memenuhi kebutuhan sendiri dan membantu ekonomi keluarga. Flourishing ialah merealisasikan potensi seseorang (baik secara spiritual, perkembangan, ekonomi, dll) berhasil, melakukan pencapaian atau berkontribusi secara signifikan bagi masyarakat [20].

Pencapaian lainnya yang telah subjek dapatkan adalah subjek mampu membangun rumah tangga yang ideal dan harmonis dengan menjalankan hak dan kewajiban sebagai istri dan sebagai seorang ibu. Sesuai dengan pemikiran Hone bahwa prestasi adalah sebuah keberhasilan individu dalam mencapai kondisi yang diinginkan, dan mencapai kemajuan menuju suatu tujuan dalam hidup [21].

\section{Kesimpulan}

Penelitian ini menemukan bahwa keenam subjek menunjukkan aspek positive emotion diberbagai aktivitas dalam hidupnya. Seperti senang, nyaman, bahagia, optomis dan bersyukur. Keenam subjek menunjukkan engagement atau keterlibatan pada setiap aktivitasnya, baik sebagai entrepreneur dan 
sebagai ibu rumah tangga. Mampu mengatur waktu antara kewajibannya sebagai ibu rumah tangga dan juga sebagai wanita entrepreneur. subjek menjalani hubungan yang positif dengan orang disekeliling subjek baik itu dengan keluarga dan juga orang-orang yang terlibat dalam pekerjaan seperti karyawan dan konsumen. Meaning of laife atau makna hidup bagi keenam subjek adalah mampu menyeimbangkan antara keluarga dan pekerjaan sebagai entrepreneur, dan keenam subjek menjadikan hal tersebut sebagai acuannya dalam menjalani aktvitas sehari-hari. Karena bagi keenam subjek keluarga tetap menjadi prioritas utama. Keenam subjek mampu mencapai keadaan hidup yang mereka inginkan. Seperti mampu membangun usaha sendiri dengan kemampuan yang juga dimiliki subjek. Selain itu Pencapaian keenam subjek lainnya ialah mampu membangun rumah tangga yang ideal dan harmonis bagi subjek.

\section{Daftar Pustaka}

[1] Law, D. M., Shapka, J. D., \& Collie, R. J. (2020). Who might flourish and who might languish ? Adolescent social and mental health profiles and their online experiences and behaviors. Human Behavior \& Emerg Tech, 2(July 2019), 82-92. https://doi.org/10.1002/hbe2.172

[2] Apreviadizy, P., \& Puspitacandri, A. (2014). Perbedaan stres ditinjau dari ibu bekerja dan ibu tidak bekerja. Jurnal Psikologi Tabularasa, 9(1).

[3] Moleong, LJ (2016). Metodologi Penelitian Kualitatif Edisi Revisi. Bandung: PT Remaja Rosdakarya

[4] Sugiyono. (2016). Metode penelitian kombinasi. Bandung:Alfabeta

[5] Sugiono, P. D. (2015). Memahami Penelitian Kualitatif. In Bandung: Alfabeta. Bandung: Alfabeta.

[6] Seligman,M.(2013).Beyond authentic happiness: Menciptakan kebahagiaan sempurna dengan psikologi positif. Bandung: Mizan Pustaka

[7] Arif, Iman S. (2016). Psikologi positif:pendekatan saintifik menuju kebahagiaan. Jakarta: Gramedia.

[8] Huppert, F. A., \& So, T. (2009). What percentage of people in Europe are flourishing and what characterises them? Briefing document for the OECD/ISQOLS meeting "Measuring subjective well-being: an opportunity for NSOs?'” 23/24 July, 2009, Florence, Italy.

[9] Keyes, C. L. M. (2002). The Mental Health Continuum : From Languishing to Flourishing in Life *. Journal of Health and Social Research, 43(2), 207-222. https://doi.org/10.2307/3090197.

[10] Keyes, C. L. M. (2015). Flourishing after addiction : An invited commentary on the McGaffin et al . Flourishing after addiction : An invited commentary on the McGaffin et al . ( 2015 ) study. Addiction Research \& Theory, OO(00), 1-3. https://doi.org/10.3109/16066359.2015.1048236

[11] Fuller-thomson, E., Agbeyaka, S., \& Bern-klug, M. (2016). Author' s Accepted Manuscript with a history of depression. Psychiatry Research. https://doi.org/10.1016/j.psychres.2016.04.041

[12] Fredrickson, B. (2009). Positivity. Three Rivers Press (CA)

[13] Effendy, N. (2016). Konsep flourishing dalam psikologi positif: subjective well-being atau berbeda. Psychology \& Humanity, 327-333.

[14] Fowers, B. J., Laurenceau, J. P., Penfield, R. D., Cohen, L. M., Lang, S. F., Owenz, M. B., \& Pasipandoya, E. (2016). Enhancing relationship quality measurement: The development of the relationship flourishing scale. Journal of Family Psychology, 30(8), 997-1007. https://doi.org/10.1037/fam0000263.

[15] Snow, N. E. (2008). Virtue and flourishing. Journal of Social Philosophy, 39(2), 225-245. https://doi.org/10.1111/j.1467-9833.2008.00425.x

[16] Frank, V.E. (2003). Logoterapi. Terapi Psikologi Pemaknaan Eksistensi. Penerjemah: M. Muntadlo. Yogyakarta: Kreasi Wacana

[17] Snyder, C.R., \& Lopez, S.J. (2007). Positive psychology. The scientific and practical explorations of human strengths. California: Sage Publication.

[18] Tasmara, T. (2001). Kecerdasan Ruhiyah. Jakarta: Gema Insani

[19] Huppert, F. A., \& So, T. T. C. (2013). Flourishing Across Europe: Application of a New Conceptual Framework for Defining Well-Being. Social Indicators Research, 110(3), 837-861. https://doi.org/10.1007/s11205-011-9966-7. 
[20] Gocken, N., Hefferon, K., and Attree, E., (2012). University students' constructions of flourishing in brittish higher education: An Inductive content analysis. Internasional Journal of Clinical Psychology, 54, 261-271.

[21] Hone, L.C., Jarden, A., Schofield, G.M., \& Duncan, S. (2014). Measuring flourishing: The impact of operational definitions on the prevalence of high levels of wellbeing. International Journal of Wellbeing, 4(1), 62-90. doi:10.5502/ijw.v4i1.4 